\title{
PENANAMAN PENDIDIKAN KARAKTER PEDULI LINGKUNGAN DI SEKOLAH DASAR
}

\author{
Arifin Muslim¹, Novica Dimar Azizah², Supriatna ${ }^{3}$, Eneng Dian Nurwulan ${ }^{4}$ \\ ${ }^{1,2,3}$ Unversitas Muhammadiyah Purwokerto, \\ ${ }^{4}$ SD Negeri 1 Bojongsari
}

\begin{tabular}{l}
\hline Article Info \\
\hline Article history: \\
Accepted April 22, 2021 \\
Published April, 2021 \\
\\
Keywords: \\
Character Education and \\
Environmental Care
\end{tabular}

Character Education and

\begin{abstract}
This research was conducted based on the indicators of character education on environmental care which aimed to find out and analyze the school curriculum, the applying process of character education during learning in the class, the implementation, supporting factors, and hampering factors in implementing character education on environmental care. This was a descriptive qualitative research which focused on the indicators that must be achieved by the school and students. The main sources of this research were the school principal, the teachers and students of second and fifth grades. The data were collected using observation, interview, and documentation with the researcher himself as the instrument. The data were then analyzed using data reduction, data display, and conclusion. The data validity in this research used triangulation technique which was source triangulation. The results showed that the implementation of character education on environmental care was done based on the school curriculum in regular activities, spontaneous activity, exemplary, and conditioning; the applying process of character education during learning in the class and at school; the implementation of character education could be seen from eight indicators which had been achieved by the school, six indicators which had been done by low and high-class students. The supporting factors were also found at school in the form of infrastructure and the role of school environment. However, there were also hampering factors such as time issue which caused less maximal implementation and the lack of giving reward to the students who had cared with environment.
\end{abstract}

\section{Corresponding Author:}

\section{Arifin Muslim,}

Program Studi Pendidikan Guru Sekolah Dasar, Universitas Muhammadiyah Purwokerto,

Jl. KH. Ahmad Dahlan, Po. Box 202 Purwokerto, Banyumas, Indonesia.

Emai: arifinmuslim@ump.ac.id

\section{How to Cite:}

Muslim,A., Azizah, N. D., Supriatna., Nurwulan, E. D. (2021). Penanaman Pendidikan Karakter Peduli Lingkungan di Sekolah Dasar. Khazanah Pendidikan-Jurnal Ilmiah Kependidikan (JIK), 15(1), 98-101 


\section{PENDAHULUAN}

Pendidikan merupakan proses dalam pembentukan karakter suatu bangsa. Hal ini sesuai dengan fungsi dan tujuan pendidikan nasional dalam pengembangan pendidikan karakter di Indonesia yang terdapat pada UU RI Nomor 20 tahun 2003 tentang Sisdiknas Pasal 3. Pendidikan di sekolah bukan hanya sebagai tempat belajar melainkan untuk membentuk peserta didik menjadi generasi muda yang cerdas dan berkarakter. Karakter yang baik dapat dibentuk dari lingkungan yang baik pula.

Permasalahan dalam pengembangan Pendidikan karakter menjadi tanggungjawab bersama. Salah satu permasalahannya yaitu siswa sering membuang sampah sembarangan yang mengakibatkan kerusakan kelestarian lingkungan sekolah. Kerusakan lingkungan yang terjadi di sekolah memperlihatkan kurangnya kesadaran siswa akan pentingnya menjaga kelestarian lingkungan. Muslich (2011:210) "menegaskan bahwa banyaknya kerusakan alam menunjukkan bahwa kesadaran pelajar bahkan kaum terdidik untuk menjaga lingkungan masih rendah". Selain itu, kurangnya fasilitas yang memadai juga mempengaruhi kebiasaan peserta didik dalam memelihara kebersihan dan keindahan lingkungan sekolah.

Pembiasaan menjaga kebersihan tidak hanya dilakukan oleh siswa, akan tetapi dilakukan oleh guru, kepala sekolah maupun warga sekolah lainnya di lingkungan sekolah. Semuanya saling bekerjasama agar dapat menjaga kelestarian dan mengurangi kerusakan lingkungan. Lingkungan yang baik akan memberikan kebaikan bagi kehidupan siswa di sekolah.

Menjaga kebersihan, kesehatan dan kelestarian lingkungan demi kebaikan peserta didik di masa mendatang merupakan alasan perlunya pendidikan karakter peduli lingkungan. Hal ini sesuai dengan hadist Rasulullah SAW yang diriwayatkan oleh Thabrani (Sumantri, 2013:286) bahwa "manusia tidak boleh kikir untuk membiayai diri dan lingkungan secara wajar untuk menjaga kebersihan agar kesehatan diri dan keluarga/ masyarakat kita terpelihara".

Hasil observasi dan wawancara awal salah satu sekolah dasar Negeri didapatkan informasi bahwa sekolah telah berusaha menjaga keindahan dan kelestarian lingkungan melalui melakukan penghijauan dan pemeliharaan lingkungan. Sekolah Dasar tersebut telah menjadi juara dalam Perlombaan Sekolah Sehat tingkat Karesidenan Barlingmascap (Banjarnegara, Purbalingga, Banyumas, dan Cilacap) pada tahun 2014. Prestasi tersebut dibuktikan dengan lingkungan sekolah yang asri, penuh dengan tanaman hijau yang sangat indah dan menjadi SD inti sebagai Gugus Adiwiyata yang memiliki kelebihan sarana dan prasarana, manajemen serta prestasi.

Penjelasan di atas, peneliti ingin menganalisis proses penanaman pendidikan karakter peduli lingkungan dalam pengembangan sekolah serta menanamkan pendidikan karakter peduli lingkungan.

\section{METODE}

Metode penelitian yang digunakan dalam penelitian ini merupakan penelitian deskriptif kualitatif. Penelitian ini bertujuan untuk menganalisis penanaman pendidikan karakter peduli lingkungan berdasarkan kurikulum, proses penanaman, implementasi, faktor pendukung, dan faktor penghambat. Sumber data dalam penelitian ini berupa data primer dan sekunder. Sumber utama penelitian adalah kepala sekolah, guru kelas II dan V, peserta didik kelas II dan V. Sumber data sekunder penelitian ini berupa dokumen, surat, dan foto kegiatan. Teknik pencarian data yagn digunakan yaitu observasi, wawancara dan dokumentasi. Instrumen penelitian adalah peneliti sendiri. Teknik Analisis data yang digunakan adalah reduksi data, penyajian data, dan penarikan kesimpulan. Selain dari itu keabsahan data penelitian ini menggunakan triangulasi yaitu triangulasi sumber dan triangulasi teknik. 


\section{HASIL DAN PEMBAHASAN}

Hasil penelitian menunjukkan bahwa sekolah telah berusaha untuk pemberian menanamkan karakter peduli lingkungan melalui pendidikan karakter. Pendidikan karakter peduli lingkungan di Sekolah telah ditanamkan berdasarkan kurikulum sekolah, proses penanaman dalam pembelajaran, dan implementasi dalam kehidupan sehari-hari. Di samping itu, terdapat faktor pendukung dan penghambat. Penanaman pendidikan karakter peduli lingkungan dilaksanakan melalui indikator-indikator peduli lingkungan yang ditentukan oleh Kemendiknas.

Kurikulum sekolah di antaranya: 1) kegiatan rutin seperti Jum'at bersih dan piket harian kelas; 2) Kegiatan spontan berupa teguran pada peserta didik yang membuang sampah sembarangan dan pujian bagi peserta didik yang telah menjaga kebersihan lingkungan; 3) Keteladanan guru dan kepala sekolah kepada peserta didik dengan memberikan contoh dan ikut serta dalam menjaga kebersihan dan kelestarian lingkungan sekolah; 4) Pengkondisian sarana dan prasarana yang sesuai dengan kebutuhan dan penempatannya. Hal tersebut sesuai dengan penjelasan Tim Adiwiyata mengenai kegiatan lingkungan berbasis partisipatif (2012:18) yang menjelaskan bahwa "warga sekolah melakukan kegiatan pemeliharaan gedung dan lingkungan sekolah antara lain: piket kebersihan kelas, Jum'at bersih, lomba kebersihan kelas, kegiatan pemeliharaan taman oleh masing- masing kelas dan lain-lain".

Proses penanaman dalam pembelajaran. Pendidikan karakter peduli lingkungan dapat ditanamkan melalui proses pembelajaran di kelas dan sekolah. Proses pembelajaran yang dilaksanakan baik di dalam kelas maupun di luar kelas berkaitan dengan pentingnya menjaga kebersihan dan kesehatan diri maupun lingkungan. Proses pembelajaran di sekolah juga dapat menanamkan pendidikan karakter peduli lingkungan melalui program bersih lingkungan sekolah. Proses pembelajaran ini sesuai penjelasan Kementerian Pendidikan Nasional (2010:20) bahwa pendidikan karakter ditanamkan melalui proses belajar pada setiap mata pelajaran atau kegiatan yang dirancang sedemikian rupa.

Implementasi pendidikan karakter peduli lingkungan melalui indikator- indikator yang telah harus dicapai sekolah dan dilaksanakan s i s w a didik kelas II dan V. Delapan Indikator yang dilaksanakan sekolah di antaranya: "a) tersedia tempat pembuangan sampah dan tempat cuci tangan; b) menyediakan kamar mandi dan air bersih; c) pembiasaan hemat energi; d) membuat biopori di area sekolah; e) membangun saluran pembuangan air limbah dengan baik; f) melakukan pembiasaan memisahkan jenis sampah organik dan anorganik; g) penugasan pembuatan kompos dari sampah organik; h) menyediakan peralatan kebersihan" Indikator karakter peduli lingkungan masing-masing enam indikator yang telah dilaksanakan peserta didik pada kelas II dan kelas V. Indikator-indikator peduli lingkungan yang telah dicapai sekolah dan peserta didik kelas II dan V sesuai dengan penjelasan Yaumi (2016:60) bahwa "peduli lingkungan adalah sikap dan tindakan yang selalu berupaya mencegah kerusakan pada lingkungan alam di sekitarnya, misalnya membuang sampah pada tempatnya".

Faktor pendukung dalam penanaman pendidikan karakter peduli lingkungan adalah sarana dan prasarana yang mendukung dan memadai serta adanya peran lingkungan sekolah (warga sekolah dan lingkungan). Hal ini didukung dengan penjelasan Mulyasa (2011:49) bahwa "bentuk sarana pendidikan seperti gedung, ruang kelas, meja, kursi, serta alat-alat dan media pengajaran serta prasarana seperti halaman, kebun, taman sekolah, dan jalan menuju sekolah disediakan untuk membuat peserta didik nyaman berada di sekolah".

Faktor penghambat tidak terlepas dalam penanaman pendidikan karakter peduli lingkungan di Sekolah yaitu kesadaran beberapa peserta didik yang masih kurang dan kendala waktu yang belum maksimal dalam pencapaian indikator peduli lingkungan di sekolah. Hal ini sesuai dengan penjelasan Fathurrohman, dkk (2017:161) menegaskan "bahwa waktu yang tersedia untuk pendidikan karakter di kelas sangat sedikit sekali, tidak mungkin dari waktu yang 
sedikit itu pembelajaran karakrer dapat dilakukan dengan sempurna walaupun menggunakan metode yang tepat”.

\section{SIMPULAN}

a. Simpulan

Berdasarkan pembahasan di atas dapat disimpulkan bahwa $\mathrm{P}$ e n di d i k a n karakter dapat ditanamkan dalam kehidupan sehari-hari di sekitar lingkungan s e k o l a h, salah satunya karakter peduli lingkungan. Penanaman pendidikan karakter peduli lingkungan di SD Negeri Kedondong dilakukan melalui indikator- indikator peduli lingkungan yang telah ditentukan Kemendiknas untuk dilaksanakan sekolah dan peserta didik. Berdasarkan hasil penelitian menunjukkan bahwa warga sekolah telah berusaha melaksanakan kurikulum sekolah berwawasan lingkungan, dalam proses pembelajaran memanfaatkan lingkungan sekolah, warga sekolah telah menerapkan delapan indikator sekolah, enam indikator yang telah dilaksanakan peserta didik kelas II dan kelas V. Keberhasilan dalam penanaman pendidikan karakter peduli lingkungan di sekolah tidak terlepas dari faktor pendukung dan penghambat. Faktor pendukung meliput sarana dan prasarana serta peran lingkungan sekolah. Faktor penghambat atau kendala waktu pelaksanaan dalam pencapaian indikator sekolah belum maksimal dan kurangnya penghargaan bagi warga sekolah yang peduli terhadap lingkunga

\section{b. Saran}

Berdasarkan kesimpulan di atas penulis mengajukan saran-saran sebagaiberikut:

1) Sekolah perlu menggerakan lagi pengelolaan atau penugasan pembuatan kompos di sekolah.

2) Sekolah perlu mengembangkan program keterampilan untuk memanfaatkan barang bekas seperti sampah plastik atau botol.

3) Sekolah perlu lebih memotivasi dengan memberikan sanksi dan reward.

\section{DAFTAR PUSTAKA}

Fathurrohman, P., AA Suryana, dan Fenny Fatriany. (2017). PengembanganPendidikan Karakter. Bandung: Refika Aditama.

Kementerian Pendidikan Nasional Badan Penelitian Dan Pengembangan Pusat Kurikulum. (2010). Pengembangan Pendidikan Budaya dan Karakter Bangsa Pedoman Sekolah. Jakarta: Kemendiknas.

Mulyasa, E. (2011). Manajemen Berbasis Sekolah. Bandung: PT Remaja Rosdakarya.

Muslich, M. (2011). Pendidikan Karakter Menjawab Tantangan Krisis Multidimensional. Jakarta: Bumi Aksara.

Sumantri, A. (2013). Kesehatan Lingkungan. Jakarta: Kencana Prenada Media Group. Tim Adiwiyata. (2012). Panduan Adiwiyata Sekolah Peduli dan Berbudaya Lingkungan. Jakarta: Kementerian Lingkungan Hidup

Yaumi, M. (2016). Pendidikan Karakter (Landasan, Pilar, dan Implementasi). Jakarta: Prenadamedia Group.

\section{http://jurnalnasional.ump.ac.id/index.php/khazanah}

